\title{
Is in vitro micrografting a possible valid alternative to traditional micropropagation in Cactaceae? Pelecyphora aselliformis as a case study
}

\author{
Ornella Badalamenti ${ }^{1}$, Angela Carra ${ }^{1}$, Elisabetta Oddo ${ }^{2}$, Francesco Carimi ${ }^{1 *}$ (D) and Maurizio Sajeva ${ }^{2}$
}

\begin{abstract}
Several taxa of Cactaceae are endangered by overcollection for commercial purposes, and most of the family is included in the Convention on International Trade in Endangered Species of Fauna and Flora (CITES). Micropropagation may play a key role to keep the pressure off wild populations and contribute to ex situ conservation of endangered taxa. One of the limits of micropropagation is the species-specific requirement of plant regulators for each taxon and sometimes even for different genotypes. With the micrografting technique the rootstock directly provides the scion with the necessary hormonal requirements. In this paper we present data on in vitro grafting of Pelecyphora aselliformis Ehrenberg, an Appendix I CITES listed species critically endangered and sought after by the horticultural trade, on micropropagated Opuntia ficus-indica Miller. Apical and sub-apical scions of P. aselliformis were used to perform micrografting with a successful rate of 97 and $81 \%$ respectively. Survival rate after ex vivo transfer was $85 \%$. We hypothesize that this method could be applied to other endangered, slow growing taxa of Cactaceae thus contributing to the conservation of this endangered family.
\end{abstract}

Keywords: CITES, Ex situ conservation, In vitro grafting, Micropropagation, Succulent plants, Tissue culture

\section{Background}

Several taxa of Cactaceae are endangered by over-collecting for commercial purposes, and most of the family is included in the Convention on International Trade in Endangered Species of Fauna and Flora (CITES) (Sajeva et al. 2012). Usually the most endangered species are slow growing, not easily propagated and seeds may be rare and high priced. The request of the market is often fulfilled through illegal collection of wild specimens (Sajeva et al. 2013). Micropropagation may play a key role to keep the pressure off wild populations (Malda et al. 1999) and contribute to ex situ conservation. In vitro culture techniques allow massive propagation of several plant taxa

\footnotetext{
*Correspondence: francesco.carimi@ibbr.cnr.it

${ }^{1}$ Institute of Biosciences and BioResources (IBBR), Research Division of Palermo, National Research Council (CNR), Corso Calatafimi 414, 90129 Palermo, Italy

Full list of author information is available at the end of the article
}

starting from a small amount of plant material and with low impact on wild populations (Iriondo and Perez 1990) including Cactaceae among others (Lema-Rumińska and Kulus 2014). One of the limits of micropropagation is the species-specific requirement of plant growth regulators (PGR) for each taxon and sometimes even for different genotypes, besides the somaclonal variation which may be induced when a callus phase is present (Larkin and Scowcroft 1981).

Grafting is widely used to propagate several horticultural taxa (Hartmann et al. 1997), to overcome rooting problems and speed growth. With the grafting technique the scion growth requirements are provided directly from the rootstock. The use of in vitro grafting may enhance the advantages of both basic techniques, as shown in some woody species (e.g. Hassanen 2013; Niang et al. 2010).

In this paper we present data on in vitro micrografting of Pelecyphora aselliformis Ehrenberg, an Appendix
勿

(C) 2016 Badalamenti et al. This article is distributed under the terms of the Creative Commons Attribution 4.0 International License (http://creativecommons.org/licenses/by/4.0/), which permits unrestricted use, distribution, and reproduction in any medium, provided you give appropriate credit to the original author(s) and the source, provide a link to the Creative Commons license, and indicate if changes were made. 
I CITES listed species critically endangered and sought after by the horticultural trade, on micropropagated Opuntia ficus-indica Miller rootstock. We have tested if this method could be a more suitable alternative for propagation of this endangered species than traditional micropropagation as reported by Giusti et al. (2002).

\section{Methods}

Seeds of O. ficus-indica were obtained from a plant cultivated at the Botanic Garden of Palermo, Italy. Seeds of $P$. aselliformis were purchased from Koehres Kakteen (Germany). To establish the in vitro cultures, sixty seeds of $O$. ficus-indica were chemically scarified with concentrated $\mathrm{H}_{2} \mathrm{SO}_{4}$ for 15 min and rinsed three times under aseptic conditions with sterile distilled water (SDW) and germinated on MS medium (Murashige and Skoog 1962) supplemented with $146 \mathrm{mM}$ sucrose and $1 \mu \mathrm{M}$ gibberellic acid $\left(\mathrm{GA}_{3}\right)(\mathrm{pH} 5.7 \pm 0.1)$. Seedlings of O. ficus-indica (Fig. 1a) were used as starting material to obtain suitable micropropagated rootstock for in vitro micrografting.
Preliminary experiments showed that the best results in terms of rootstock production were obtained when explants were cultured in presence of $2 \mu \mathrm{M}$ 6-benzylaminopurine (BA). This plant material was subcultured every 30 days and maintained as rootstock source indefinitely (Fig. 1b).

Forty-five seeds of $P$. aselliformis were disinfected for $1 \mathrm{~min}$ in $70 \%$ ethanol, $25 \mathrm{~min}$ in $2 \%$ sodium hypochlorite $(w / v)$, rinsed four times under aseptic conditions with SDW and germinated on MS medium (Fig. 1c).

All cultures were maintained in a climate chamber at $25 \pm 1{ }^{\circ} \mathrm{C}$ under a $16 \mathrm{~h}$ day length, and a photosynthetic photon flux of $50 \mu \mathrm{mol} \mathrm{m} \mathrm{m}^{-2} \mathrm{~s}^{-1}$ provided by Osram coolwhite $18 \mathrm{~W}$ fluorescent lamps.

Micrografts were carried out using O. ficus-indica as rootstock and $P$. aselliformis seedlings as scion. Micrografting procedures were based upon those described by Estrada-Luna et al. (2002) with few modifications. Micrografts were performed on $10 \mathrm{~mm}$ long fresh cut rootstock of $O$. ficus-indica without roots. Shoots were cut under
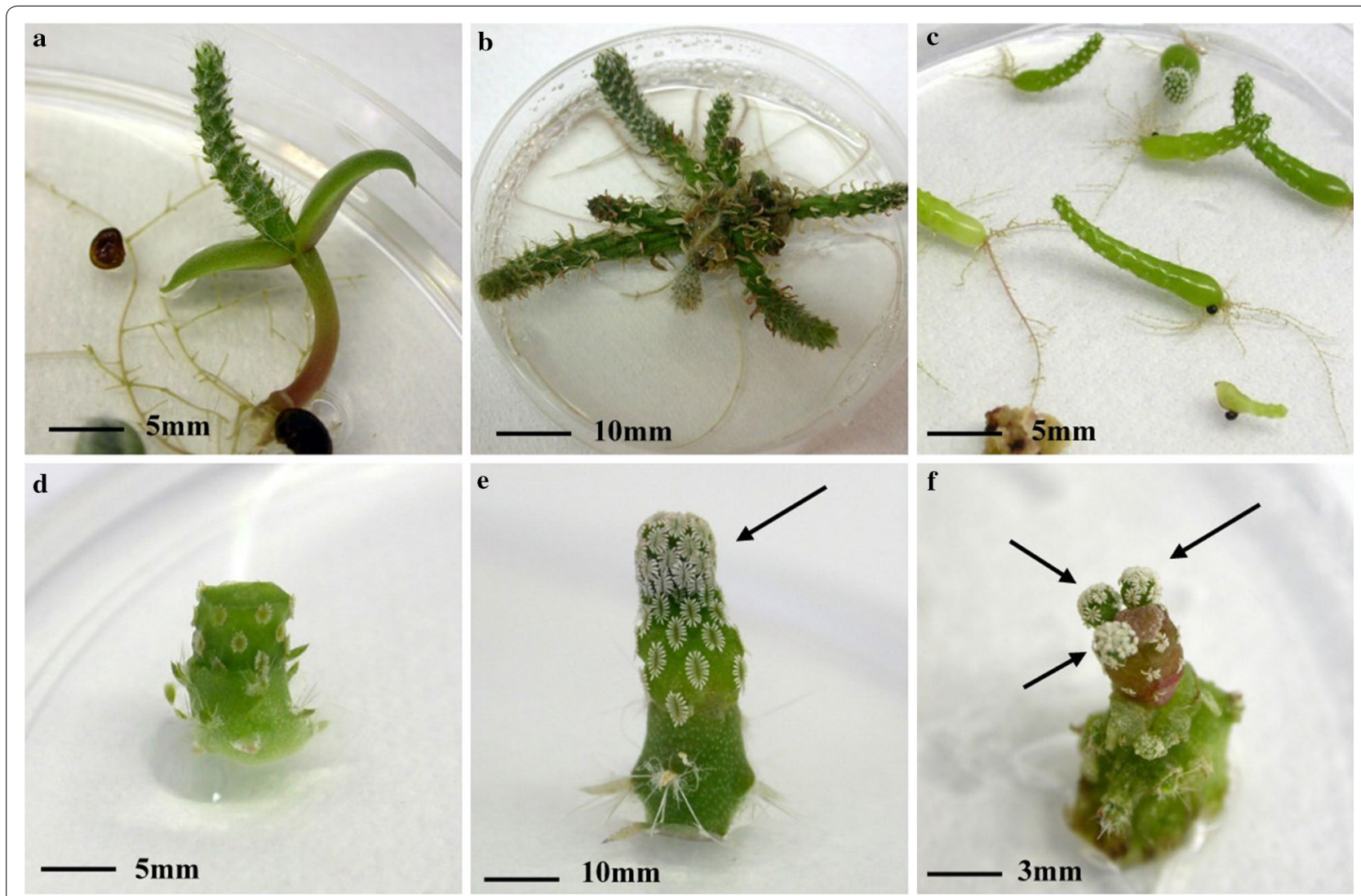

Fig. 1 Different stages of micrografting procedures: a Seedling of Opuntia ficus-indica 30 days after sowing; b Opuntia ficus-indica subcultured and maintained as rootstock source indefinitely; c Seedlings of Pelecyphora aselliformis 60 days after sowing; $\mathbf{d}$ Freshly grafted sub-apical slice of Pelecyphora aselliformis on micropropagated Opuntia ficus-indica; e Micrografting of the apical part of Pelecyphora aselliformis after 20 days of cultivation. Arrow indicates new growth; $\mathbf{f}$ Micrografting of a sub-apical slice of Pelecyphora aselliformis after 20 days of cultivation. Arrows indicate new shoots arising from three different areoles 
aseptic conditions at the base and at the top with a single stroke of a razor blade. The scion was cut into apical and sub-apical segments (slices) of 5 and $3 \mathrm{~mm}$, respectively. To maximize the production of slices no areoles were left in the remaining hypocotyl. The remaining part was discarded.

The freshly cut scion was brought in contact with freshly cut rootstock tissue (Fig. 1d), the two bionts were incubated on medium to induce root formation. Periodically, axillary shoots that emerged from rootstocks were removed. The different steps of micrografting were carried out on PGR free MS medium and maintained as described above. Micrografts were done in separate batches. When sub apical explants were used, each set comprised 90 micrografts while, when apical explants were used, each set was of ten micrografts.

Well developed micrografts $25 \mathrm{~mm}$ long were collected and washed in SDW to remove the medium, then transferred into autoclaved Jiffy $7^{\circledR}$ peat pellets soaked in $40 \mathrm{ml}$ of SDW. After transplanting, plants were maintained under $95 \pm 5 \%$ relative humidity in a growth chamber till roots grew out of the pellet, and then transferred to the greenhouse, exposed to daylight conditions at $25 \pm 2{ }^{\circ} \mathrm{C}$ day, $20 \pm 2{ }^{\circ} \mathrm{C}$ night. Micrografting response was quantified by the number of non-necrotic scions and the number of offsets produced by the scions 60 days after micrografting. Scion growth was evaluated by recording the mean number of new shoots and the shoot length 3 and 6 weeks after grafting.

\section{Results}

Germination of O. ficus-indica started about 30 days after sowing (Fig. 1a) and germination frequency was $75 \%$ after three months. Successfully germinated seedlings (45) reached $30-40 \mathrm{~mm}$ in length within 3 months after germination with a mean diameter of the epicotyl of $5 \mathrm{~mm}$. Plantlets of O. ficus-indica produced the first shoots from the areoles 15 days after culture initiation, and after 30 days the mean number of shoots produced from areoles was 7.4 per explant with a mean shoot length of $17 \mathrm{~mm}$ (Fig. 1b).

Germination of seeds of $P$. aselliformis occurred gradually starting 20 days after sowing and germination frequency was $73.3 \%$. Successfully germinated seedlings (33) reached $40 \mathrm{~mm}$ in length within 3 months after germination with a mean diameter of $5 \mathrm{~mm}$. Seedlings were considered suitable for micrografting when they were at least $10 \mathrm{~mm}$ long (Fig. 1c).

To maximize the productivity, sub-apical slices of P. aselliformis $3 \mathrm{~mm}$ in length were used for grafting (Fig. 1d). Each slice had at least one areole, which potentially can produce new shoots. Preliminary experiments showed that rootstock with a diameter between 4 and
$6 \mathrm{~mm}$ gave the best results in grafting compatibility. In total we used 30 apical scions $(\approx 150 \mathrm{~mm}$ total length) and 270 sub-apical slices corresponding to $\approx 810 \mathrm{~mm}$, excluding the part below the cotyledons which has no areoles.

No problems were observed during union formation and only a small percentage $(10 \%)$ of graft failure occurred due to scion displacement. $81 \%$ of micrografts were successful and gave rise to new individuals. The reestablishment of growth of the scion was evident 3 weeks after micrografting (Table 1; Fig. 1e-f). Six weeks after micrografting $90 \%$ of successful micrografts developed roots. When the mean length of the scion ranged from 35 to $40 \mathrm{~mm}$ grafted plants were considered suitable for a new multiplication cycle or for in vivo transfer. For in vivo transfer, grafts with a well developed root apparatus were transplanted in Jiffy pots and 2 months after the in vivo transfer, the survival rate was of $85 \%$ (Table 1 ).

\section{Discussion}

The use of PGR may induce somaclonal variation in different regeneration systems in vitro, as reported for many species, including several members of Cactaceae (Corneanu et al. 1990; Mangolin et al. 1994). Our results show that by micrografting it is possible to propagate $P$. aselliformis in vitro without adding combinations of PGR to the culture medium. In this way there is no need to test the genetic stability of regenerants. Additionally, it is not necessary to carry out time-consuming preliminary tests to find the ideal PGR requirements for micropropagation, or to analyse the endogenous hormonal content as in Sriskandarajah et al. (2006) because the rootstock directly provides the scion with the required hormones (Webster 1994). Moreover the use of PGR often induces callus production from which shoots emerge with a very high incidence of hyperhydricity (Giusti et al. 2002). This is a further reason for which the establishment of a multiplication procedure with no PGR added should be preferred for endangered plants.

Our in vitro cultured plants showed a faster growth rate compared to soil-grown ones, as reported by Giusti et al. (2002). The number of grafted plants produced was two per centimetre of seedling for the first propagation cycle, which was less than that obtained by Giusti et al. (2002); however, it was possible to produce plants with no hyperhydricity and avoid the need of preliminary in vitro proliferation cycles as described by Pérez-Molphe-Balch and Dàvila-Figueroa (2002). Furthermore, the newly obtained plants could be used for subsequent propagation cycles.

These results clearly show that it is possible to micrograft small apical and sub-apical slices $(5$ and $3 \mathrm{~mm}$, respectively) of $P$. aselliformis onto $O$. ficus-indica rootstock, obtaining a good percentage of successful grafts 


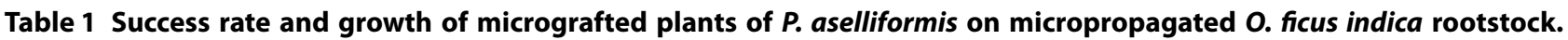
Mean \pm SE

\begin{tabular}{|c|c|c|c|c|c|c|c|}
\hline \multirow[t]{2}{*}{ Type of scion } & \multirow{2}{*}{$\begin{array}{l}\text { No. of } \\
\text { micrografts }\end{array}$} & \multirow{2}{*}{$\begin{array}{l}\text { Successful } \\
\text { micrografts (\%) }\end{array}$} & \multicolumn{3}{|c|}{ Scion growth } & \multirow{2}{*}{$\begin{array}{l}\text { Rooted } \\
\text { micrograft (\%) }\end{array}$} & \multirow{2}{*}{$\begin{array}{l}\text { Successful ex vivo } \\
\text { transfer (\%) }\end{array}$} \\
\hline & & & $\begin{array}{l}\text { Mean No. } \\
\text { of shoots }\end{array}$ & $\begin{array}{l}\text { Shoot } \\
\text { length } \\
(\mathrm{mm})^{\mathrm{a}}\end{array}$ & $\begin{array}{l}\text { Shoot } \\
\text { length } \\
(\mathrm{mm})^{\mathbf{b}}\end{array}$ & & \\
\hline Sub-apical & 270 & $81 \pm 1.2$ & $2.7 \pm 0.3$ & $28 \pm 0.4$ & $35 \pm 0.5$ & $90 \pm 1.2$ & $85 \pm 0.8$ \\
\hline Apical & 30 & $97 \pm 0.7$ & $1.0 \pm 0$ & $31 \pm 0.6$ & $38 \pm 0.3$ & & \\
\hline
\end{tabular}

a Three weeks after micrografting

b Six weeks after micrografting

and the production of new specimens. Furthermore in vitro grafted plants may constitute a suitable tool for ex situ conservation. On-going research on different species of Cactaceae is testing if this method is suitable for other endangered species. The micrografting technique fulfils the definition of artificial propagation as requested by CITES and does not cause damage to the wild populations of the species and therefore can be considered "non detrimental" for the wild populations.

\section{Conclusions}

This study describes the protocol for micrografting of an endangered Cactaceae, Pelecyphora aselliformis. Our results indicate that it is possible to start massive propagation with just a few seeds without the need to find the optimal in vitro requirements, which are species-specific, and to some extent genotype-specific. This technique could further be useful for the massive production of ornamental plants reducing the overharvesting of endangered species from the wild. Moreover, the production of micrografted plants may contribute also to ex situ conservation of this threatened species.

\section{Authors' contributions}

$\mathrm{OB}, \mathrm{AC}, \mathrm{FC}$ and MS conceived and designed the study; MS provided plant material; $\mathrm{OB}$ and $\mathrm{AC}$ developed the methodology and performed the experiments; $\mathrm{OB}, \mathrm{AC}, \mathrm{EO}$ and $\mathrm{MS}$ analysed data. All authors discussed the results and prepared the manuscript. All authors read and approved the final manuscript.

\section{Author details \\ ${ }^{1}$ Institute of Biosciences and BioResources (IBBR), Research Division of Palermo, National Research Council (CNR), Corso Calatafimi 414, 90129 Palermo, Italy. ${ }^{2}$ Department of Biological, Chemical and Pharmaceuti- cal Science and Technology (STEBICEF), University of Palermo, via Archirafi 18, 90123 Palermo, Italy.}

\section{Competing interests}

The authors declare that they have no competing interests.

\section{Funding}

This work was funded in part by the University of Palermo (Fondi di Ateneo ex quota $60 \%, 2007$ to MS).

Received: 1 November 2015 Accepted: 17 February 2016
Published online: 27 February 2016

\section{References}

Corneanu MM, Corneanu GC, Copacescu SN (1990) Plant regeneration with somaclonal variability from Mammillaria sp. callus. In: Abstracts of the VIlth International Congress on Plant Tissue and Cell Culture, Abstract A3-66, p. 99

Estrada-Luna AA, Lopez-Peralta C, Cárdenas-Soriano E (2002) In vitro micrografting and the histology of graft union formation of selected species of prickly pear cactus (Opuntia spp.). Sci Hortic 92:317-327

Giusti P, Vitti D, Fiocchetti F, Colla G, Saccardo F, Tucci M (2002) In vitro propagation of three endangered cactus species. Sci Hortic 95:319-332

Hartmann HT, Kester DE, Davies FT (1997) Plant propagation: principles and practices, 6th edn. Prentice Hall, New Jersey

Hassanen SA (2013) In vitro grafting of pear (Pyrus spp.). World Appl Sci J 21:705-709

Iriondo JM, Perez C (1990) Application of in vitro culture techniques to the conservation of Iberian endemic endangered plant species. Bot Gard Micropropag News 1:4-6

Larkin PJ, Scowcroft WR (1981) Somaclonal variation a novel source of variability from cell cultures for plant improvement. Theor Appl Genet 60:197-214

Lema-Rumińska J, Kulus D (2014) Micropropagation of Cacti-a review. Haseltonia 19:46-63

Malda G, Suzán H, Backhaus R (1999) In vitro culture as a potential method for the conservation of endangered plants possessing crassulacean acid metabolism. Sci Hortic 81:71-87

Mangolin CA, Prioli AJ, Machado MFPS (1994) Isozyme patterns in callus culture and in plants regenerated from calli of Cereus peruvianus. Biochem Genet 32:237-247

Murashige T, Skoog F (1962) A revised medium for rapid growth and bioassays with tobacco tissue culture. Physiol Plant 15:473-497

Niang D, Gassama YK, Ndiaye A, Sagna M, Ndiaye NSA, Toure MAI (2010) In vitro micrografting of Sterculia setigera Del. Afr J Biotechnol 9:8613-8618

Pérez-Molphe-Balch E, Dàvila-Figueroa CA (2002) In vitro propagation of Pelecyphora aselliformis Ehrenberg and P. strobiliformis Werdermann (Cactaceae). In Vitro Cell Dev Biol Plant 38:73-78

Sajeva M, McGough HN, Garrett L, Lüthy J, Tse-Laurence M, Rutherford C, Sajeva G (2012) CITES and Cacti a user's guide. Kew Publishing, Royal Botanic Gardens, Kew

Sajeva M, Augugliaro C, Smith M, Oddo E (2013) Regulating internet trade in CITES species. Conserv Biol 27:429-430

Sriskandarajah S, Prinsen E, Motyka V, Dobrev PI, Serek M (2006) Regenerative capacity of Cacti Schlumbergera and Rhipsalidopsis in relation to endogenous phytohormones, cytokinin oxidase/dehydrogenase, and peroxidase activities. J Plant Growth Regul 25:79-88

Webster T (1994) Rootstock and interstock effects on deciduous fruit tree growth and cropping — a brief review. Compact Fruit Tree 27:5-16 